\title{
Role of Zinc Deficiency in Development of Minimal Hepatic Encephalopathy among HCV Induced Compensated Cirrhotic Patients
}

\author{
Ibrahim M. Ibrahim ${ }^{1}$ and Amany M. Sediq ${ }^{2}$ \\ ${ }^{1}$ Tropical Medicine Department, Faculty of Medicine, Zagazig University,Egypt. \\ ${ }^{2}$ Clinical Pathology Department, Faculty of Medicine, Zagazig University, Egypt.
}

Corresponding Author Ibrahim M. Ibrahim

Mobile: 01225771945

E mail:

Ibrahimibrahim1979@ yahoo. com

Key words: Minimal hepatic encephalopathy, zinc deficiency and zinc supplementation
Background and study aim: Minimal hepatic encephalopathy is a term used to describe cirrhotic patients who are clinically normal but show abnormalities of neurophysiological variables and/or cognition. Implicated theories of pathogenesis are similar to those of overt hepatic encephalopathy. Hypozincaemia was studied as a theory for the pathogenesis of overt hepatic encephalopathy. The aim of the present study is to evaluate the role of hypozincaemia in development of minimal hepatic encephalopathy among $\mathrm{HCV}$ induced compensated cirrhotic patients.

Patients and Methods: 30 patients with $\mathrm{HCV}$ induced compensated liver cirrhosis with minimal hepatic encephalopathy were studied versus 30 patients with HCV induced compensated liver cirrhosis without minimal hepatic encephalopathy. Diagnosis of minimal hepatic encephalopathy was based on positivity of both Number Connection Tests A and B. Serum zinc was evaluated for all subjects. Zinc deficient minimal hepatic encephalopathy patients were supplemented with zinc sulphate heptahydrate $220 \mathrm{mg}$ daily for 1 month before $\mathrm{HCV}$ treatment and scores of Number Connection Tests A and B were redetermined.

Results: Serum zinc is significantly lower in patients with minimal hepatic encephalopathy than in those without minimal hepatic encephalopathy. Scores of Number Connection Tests A and B among zinc deficient patients with minimal hepatic encephalopathy were significantly improved after zinc supplementation.

Conclusion: Zinc deficiency may play a role in development of minimal hepatic encephalopathy among patients with HCV induced compensated liver cirrhosis. Zinc supplementation is recommended for the treatment of minimal hepatic encephalopathy among those patients.

\section{INTRODUCTION}

Zinc is an important trace element and is a constituent of many metal-protein complexes such as metalloenzymes. It has a pivotal role in the regulation of protein metabolism, immune responsiveness and membrane integrity. A group of disorders have been reported in patients with chronic liver disease which may reflect hypozincaemia. These abnormalities include taste and smell abnormalities, photoreceptor dysfunction, immune dysfunction and hypogonadism [1]. Hypozincaemia affects nitrogen metabolism by impairing the activity of urea cycle enzymes in liver [2] and by reducing the activity of glutamine synthetase in muscles [3]. It has also been reported that hypozincaemia may have a role in the pathogenesis of overt hepatic encephalopathy as serum zinc concentrations are decreased in patients with this condition and are inversely correlated with arterial concentrations of blood ammonia [4].

Minimal hepatic encephalopathy is a term used to describe cirrhotic patients who are clinically normal but show abnormalities of neurophysiological variables and/or cognition [5]. It negatively affects health related quality of life and the ability to perform complex tasks such as driving [6]. It also increases the risk of developing overt hepatic encephalopathy [7].

Impaired psychometric performance defines the presence of minimal hepatic 
encephalopathy in cirrhotic patients who appear clinically normal. Patients with minimal hepatic encephalopathy show deficits in attention, fine motor skills and working memory while other cognitive abilities are relatively preserved. Patients with overt hepatic encephalopathy show additional disturbances in psychomotor speed, executive function and concentration [8].

Promising results have been obtained using a group of paper and pencil neuropsychological tests; namely Number connection tests A and B, Figure connection test, Line racing test, Circle dotting, Serial-dotting test and Digit symbol test. This battery of tests is called the Psychometric Hepatic Encephalopathy Score (PHES) and is used to assess the required domains of attention, concentration, memory, visual perception, visuospatial orientation and visuoconstructive abilities. They are easily applicable and have been shown to have a high specificity for the diagnosis of minimal hepatic encephalopathy $[\mathbf{5 , 8}]$.

\section{PATIENTS AND METHODS}

This case-control study was conducted in Tropical Medicine and Clinical Pathology departments, Zagazig University hospitals in the period from January to June, 2017. Cases and controls were recruited from the HCV treatment unit affiliated to Tropical Medicine Department, Zagazig University hospitals. The study included 60 patients classified into two groups; first group (GI) of 30 patients with HCV induced compensated liver cirrhosis with minimal hepatic encephalopathy and second group (GII) of 30 patients with HCV induced compensated liver cirrhosis without minimal hepatic encephalopathy. Categorization of patients into either group was based upon the scores of both Number Connection Tests A and B. Positivity of both tests defines MHE. All participants gave a written consent to be included in the study.

All compensated cirrhotic patients in G I and G II had no evident clinical abnormalities, were on average dietary constitution with no intentional protein restrictions, had no constipation and not intentionally taking medical, herbal nor dietary laxatives and were not taking diuretics.
Patients with history of overt hepatic encephalopathy, those taking alcohol, those with history of a neurologic disease (eg, previous stroke), those with extremes of BMI and those with history of diuretic intake within one week prior to estimation of their serum zinc were excluded from the study.

All study participants were subjected to complete history taking and clinical examination. Routine laboratory investigations in the form of CBC, LFT, $\mathrm{PT}$ and INR and pelviabdominal ultrasonography were done for all study participants. Diagnosis of liver cirrhosis was based upon laboratory parameters (low platelet count, elevated AST/ALT ratio) and sonographic parameters (small right lobe, enlarged caudate lobe, undulated surface, coarse echopattern, irregular hepatic veins, dilated portal vein, collaterals and splenomegaly) [9]. Diagnosis of compensation was based upon clinical (absent symptoms and signs of liver disease), laboratory (normal serum albumin, bilirubin and prothrombin concentrations) and sonographic (absent ascites) grounds.

Two psychometeric tests (Number Connection Tests A and B) were applied to all cirrhotic patients included in the study to detect minimal hepatic encephalopathy and to give a score for each patient [10]. Minimal hepatic encephalopathy among cirrhotic patients was diagnosed by positivity of both Number connection tests $A$ and $\mathrm{B}$; both of which are tests of visuo-spatial orientation and psychomotor speed. The subject is given a sheet of paper with 25 circles which are randomly spread over the paper. In NCT-A, the task is to connect the circles 1-A-2-B-3-C and so on until L-13 as quick as possible. In NCT-B, the task is to connect circles 1 through 25 as quick as possible. Numbers and letters are written in arabic and the patient is shown a demonstration. Test result is the time needed by the patient to complete the test including error correction time. In this work, NCT is considered abnormal when the time taken by the patient to complete the test is greater than mean $+2 \mathrm{SD}$ from that of healthy controls (more than 47 seconds). 


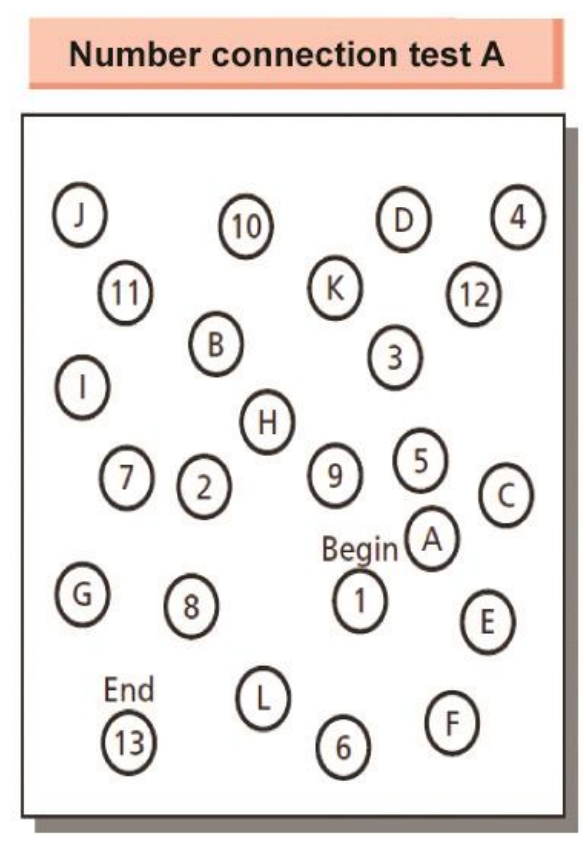

Serum zinc level estimation was performed for all study individuals by colorimetric method using commercially available kit (zinc assay kit, Segma-Aldrich, Germany). Minimum of two ml of venous blood was collected by venipuncture on a sterile red-capped vacutainer (Becton Dickinson Laboratories, Franklin Lakes, NJ, USA). Blood was incubated at $37^{\circ} \mathrm{C}$ for $10-20$ min till complete clot formation. Serum was separated in blood samples by centrifugation at $1800-2000 \mathrm{rpm}$ for 15 minutes. Serum was deproteinized using 7\% TCAA. Aliquots from supernatant were stored at $-70^{\circ} \mathrm{C}$ for later analysis. Normal serum zinc is $80-150 \mu \mathrm{g} / \mathrm{dL}$. Zinc deficiency was defined when serum zinc concentration $<80 \mu \mathrm{g} / \mathrm{dL}$.

Zinc deficient patients with HCV induced compensated liver cirrhosis and minimal hepatic encephalopathy were supplemented with zinc sulphate heptahydrate $220 \mathrm{mg} /$ day equivalent to $50 \mathrm{mg} /$ day of elemental zinc divided into two doses for one month before HCV treatment and Number Connection tests A and B were repeated

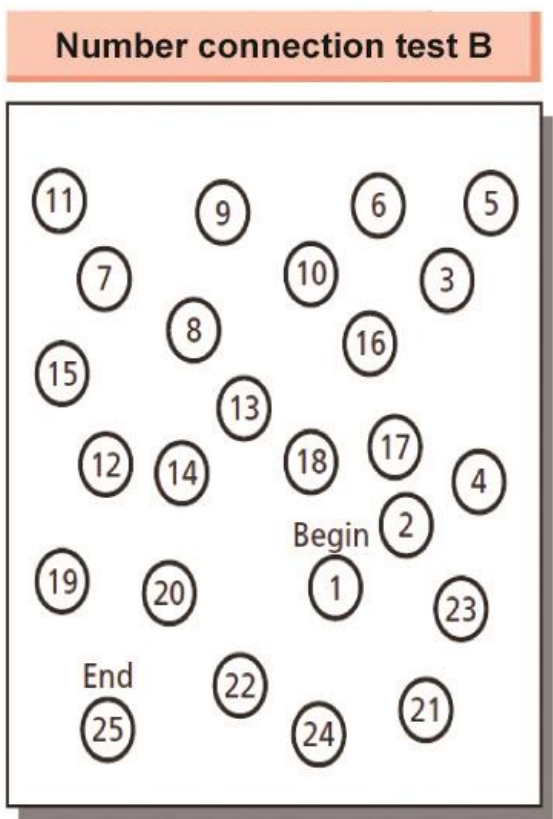

and test scores were compared with those before zinc supplementation.

Data were checked, entered and analyzed using SPSS version 19 for data processing and statistics. Continuous data were expressed as mean \pm SD and categorical data were expressed as number (percentage). Continuous data were checked for normality by using KolmogorovSmirnov test. Student t-test was used to compare two groups of normally distributed continuous data and Mann-Whitney U (MW) test was used to compare two groups of non-normally distributed continuous data. Categorical data were compared using the Chi-square $\left(\chi^{2}\right)$ test. For the previously mentioned statistical tests, the threshold of significance was fixed at $5 \%$ level ( $\mathrm{P}$ value). $\mathrm{P}$ value of $>0.05$ indicates non-significant results. $\mathrm{P}$ value of $<0.05$ indicates significant results. $\mathrm{P}$ value of $<0.001$ indicates highly significant results. The smaller the $\mathrm{P}$ value obtained, the more significant are the results. 


\section{RESULTS}

Table (1): Baseline characteristics of the studied groups

\begin{tabular}{|c|c|c|c|c|}
\hline & $\begin{array}{c}\text { G1 } \\
\text { Patients with } \\
\text { MHE }\end{array}$ & $\begin{array}{c}\text { G2 } \\
\text { Patients } \\
\text { without MHE }\end{array}$ & P value & Significance \\
\hline Age & $54.5 \pm 9.6$ & $55.8 \pm 9.2$ & 0.6 & NS \\
\hline $\operatorname{Sex}(M / F)$ & $19 / 11$ & $18 / 12$ & 0.92 & NS \\
\hline BMI & $27.1 \pm 3.5$ & $26.7 \pm 2.8$ & 0.61 & NS \\
\hline $\mathrm{Hb}(\mathrm{gm} / \mathrm{dL})$ & $12.8 \pm 2.7$ & $13.1 \pm 2.5$ & 0.77 & NS \\
\hline $\begin{array}{l}\text { WBC }\left(\times 1^{3}{ }^{3}\right. \\
\text { cells/ } / \mathrm{mL})\end{array}$ & $6.3 \pm 1.8$ & $6.1 \pm 1.9$ & 0.71 & NS \\
\hline $\begin{array}{l}\text { PIt }\left(\mathbf{x ~ 1 0} 0^{3}\right. \\
\text { cells/ } \mathbf{m L})\end{array}$ & $92 \pm 37$ & $85 \pm 40$ & 0.8 & NS \\
\hline $\begin{array}{c}\text { ALT (U / } \\
\text { liter) }\end{array}$ & $69 \pm 20$ & $68 \pm 18$ & 0.82 & NS \\
\hline AST (U / liter) & $70 \pm 22$ & $67 \pm 20$ & 0.65 & NS \\
\hline $\begin{array}{c}\text { Albumin (g / } \\
\text { dL) }\end{array}$ & $3.4 \pm 0.4$ & $3.7 \pm 0.4$ & 0.11 & NS \\
\hline $\begin{array}{c}\text { Bilirubin (mg } \\
\text { / dL) }\end{array}$ & $1.38 \pm 0.4$ & $1.4 \pm 0.4$ & 0.89 & NS \\
\hline $\begin{array}{l}\text { Prothrombin } \\
\text { time (seconds) }\end{array}$ & $12.5 \pm 1.6$ & $12.1 \pm 1.5$ & 0.85 & NS \\
\hline $\begin{array}{l}\text { Liver span } \\
\text { (cm) }\end{array}$ & $16.4 \pm 2.3$ & $16.5 \pm 2.1$ & 0.9 & NS \\
\hline $\begin{array}{l}\text { Splenic axis } \\
(\mathrm{cm})\end{array}$ & $15.1 \pm 3.5$ & $14.8 \pm 3.1$ & 0.78 & NS \\
\hline $\begin{array}{c}\text { Portal vein } \\
\text { diameter } \\
(\mathrm{mm})\end{array}$ & $13.6 \pm 0.8$ & $13.5 \pm 0.7$ & 0.9 & NS \\
\hline $\begin{array}{c}\text { Portosystemic } \\
\text { collaterals }\end{array}$ & $18 / 30(60 \%)$ & $5 / 30(16.7 \%)$ & 0.04 & $\mathrm{~S}$ \\
\hline $\begin{array}{l}\text { NCT-A score } \\
\text { (seconds) }\end{array}$ & $70 \pm 5$ & $41 \pm 6$ & $<0.001$ & HS \\
\hline $\begin{array}{l}\text { NCT-B score } \\
\text { (seconds) }\end{array}$ & $64 \pm 11$ & $35 \pm 10$ & $<0.001$ & HS \\
\hline $\begin{array}{l}\text { Serum zinc } \\
(\mathrm{mcg} / \mathrm{dL})\end{array}$ & $66 \pm 5$ & $85 \pm 4$ & $<0.001$ & HS \\
\hline
\end{tabular}

Table (2): Number of zinc deficient patients in both groups

\begin{tabular}{|c|c|c|c|c|}
\hline & $\begin{array}{c}\text { G1 } \\
\text { Patients with } \\
\text { MHE (30 } \\
\text { patients) }\end{array}$ & $\begin{array}{c}\text { G2 } \\
\text { Patients without } \\
\text { MHE (30 } \\
\text { patients) }\end{array}$ & P value & Significance \\
\hline $\begin{array}{c}\text { Low serum } \\
\text { zinc }\end{array}$ & $\begin{array}{c}23 / 30 \\
(76.7 \%)\end{array}$ & $\begin{array}{c}4 / 30 \\
(13.3 \%)\end{array}$ & $<0.001$ & HS \\
\hline $\begin{array}{c}\text { Normal } \\
\text { serum zinc }\end{array}$ & $\begin{array}{c}7 / 30 \\
(23.3 \%)\end{array}$ & $\begin{array}{c}26 / 30 \\
(86.7 \%)\end{array}$ & $<0.001$ & HS \\
\hline
\end{tabular}


Table (3): Number Connection Test results before and after zinc supplementation in zinc deficient patients (23 patients) with HCV induced compensated liver cirrhosis and minimal hepatic encephalopathy

\begin{tabular}{|c|c|c|c|c|}
\hline NCT & $\begin{array}{c}\text { Score before zinc } \\
\text { supplementation } \\
\text { (seconds) }\end{array}$ & $\begin{array}{c}\text { Score after zinc } \\
\text { supplementation } \\
\text { (seconds) }\end{array}$ & P value & Significance \\
\hline A & $69 \pm 4$ & $50 \pm 5$ & $<0.001$ & HS \\
\hline B & $60 \pm 7$ & $45 \pm 6$ & $<0.001$ & HS \\
\hline
\end{tabular}

\section{DISCUSSION}

Minimal hepatic encephalopathy is not uncommon complication of liver cirrhosis. Dhiman et al. [11] reported that the prevalence of minimal hepatic encephalopathy among compensated cirrhotic patients varied between $22 \%$ and $74 \%$ depending on the time and the number of psychometric tests used and the severity of the liver disease.

Many studies proposed the role of zinc deficiency in the pathogenesis of overt and minimal hepatic encephalopathy $[\mathbf{1 2 , 1 3 , 1 4 ]}$. Zinc acts as a coenzyme for urea cycle enzymes and may be deficient in patients with liver cirrhosis especially if associated with protein malnutrition, maldigestion and malabsorption [2].

Previous studies assessing the role of zinc deficiency on development of minimal hepatic encephalopathy were performed on patients not specifically complicating chronic HCV infection and included cirrhotic patients of all grades of liver cirrhosis. The aim of the present work is to study the role of zinc deficiency in development of minimal hepatic encephalopathy among a group of patients with $\mathrm{HCV}$ induced compensated liver cirrhosis to assess non-traditional factors of the pathogenesis helping to give a chance for a new line for treatment of such a problem which negatively affects the quality of life of cirrhotic patients and puts them at risk of accidents and of developing overt hepatic encephalopathy.

In this study, there was a highly significant statistical difference between both studied groups as regard scores of Number Connection Tests A and $\mathrm{B}$. This reflects that selection of patients in either group was based upon scores of both tests. We adopted positivity of both tests to define MHE. Weissenborn et al. [15] reported that combination of both NCT A and B is a sensitive method for diagnosis of early HE.
Mean age of patients with MHE is 54.5 years compared with a mean age of 55.8 years for patients without MHE with a non-significant difference between both means. This result indicates the fact that age is not an included risk factor for the development of MHE.

In this study, 19 patients with MHE were males and 11 were females while 18 patients without MHE were males and 12 were females. This non-significant difference in male-to-female ratio between both groups indicates that gender is not an included risk factor for the development of MHE. Male-to-female ratio of $\mathrm{HCV}$ induced liver cirrhosis is approximately $1.5: 1$. This is in agreement with Abd El Wahab et al. [16] who stated a ratio of 1.25:1. These figures reflect the fact that males are more commonly exposed to infection than females and to the fact that females may clear viremia better than males [17].

As regard to routine laboratory parameters, there was a non-significant difference between both groups as regard CBC and liver function tests. Serum albumin was higher in the group of HCV induced compensated liver cirrhosis without MHE compared with those with MHE but the statistical difference did not reach the level of significance. The relative hypoalbuminemia among patients with MHE reflects protein malnutrition among these patients. This is in agreement with Van der Rijt et al. [18] who reported a similar state of protein malnutrition among a group of patients with overt HE.

As regard to sonographic parameters, there was a non-significant difference between both groups as regard liver span, splenic axis and portal vein diameter. This non-significant difference can be explained by the fact that patients in both groups were $\mathrm{HCV}$ induced compensated liver cirrhotic patients. As regard to portosystemic collaterals, there was a significant difference between both 
groups being more common among the group of MHE. This finding is in agreement with Tarantino et al. [19] who reported a strong relationship between portosystemic collaterals and ammoniacal encephalopathy.

The difference in both serum zinc concentration and number of zinc deficient patients between the two groups are statistically highly significant. Serum zinc concentration in the group of compensated liver cirrhosis with MHE is lower than that in the group of compensated liver cirrhosis without MHE (mean $66 \mu \mathrm{g} / \mathrm{dL}$ vs 85 $\mu \mathrm{g} / \mathrm{dL}$ ). Number of zinc deficient patients in the group of compensated liver cirrhosis with MHE is higher than that in the group of compensated liver cirrhosis without MHE (23/30 vs 4/30).

Postulated pathogenetic mechanisms of hypozincaemia in a sector of cirrhotic patients include inadequate intake of zinc-rich protein diet, alcohol-induced malabsorption and the influence of cytokines espicially interleukin-6 which is well known to decrease zinc metabolism [20]. Increase urinary zinc excretion in patients with cirrhosis seems related to the impairment of albumin synthesis. The decrease in serum albumin and the increase of free amino acid concentration in cirrhosis cause displacement of zinc bound from the macromolecular ligand that result in the increase of zinc filtration in the renal glomerulus [21].

In 2004, Yang et al. [13] studied the role of hypozincaemia on development of subclinical hepatic encephalopathy among 20 non-alcoholic cirrhotic patients most of them were HBV induced and some of them had decompensated liver disease. Their findings agree with the results of the present study namely the presence of a correlation between hypozincaemia and development of MHE among HCV induced compensated cirrhotic patients.

On supplementing zinc-deficient minimal hepatic encephalopathy patients with zinc sulphate heptahydrate $220 \mathrm{mg} /$ day (equivalent to $50 \mathrm{mg}$ / day elemental zinc), mean scores of NCT A and B improved with a highly significant statistical difference. This finding is similar to that obtained by Mousa et al. [22] who supplemented a group of compensated and decompensated liver cirrhotic patients with zinc and antioxidants for 3 months and found a significant improvement of scores of psychometric tests they adopted after supplementation.
In conclusion, the lowered serum zinc among $\mathrm{HCV}$ induced compensated cirrhotic patients with minimal hepatic encephalopathy and the improvement of scores of NCT A and B of zinc deficient patients after zinc supplementation suggest a role of hypozincaemia in development of minimal hepatic encephalopathy.

Funding: None.

Conflicts of interest: None.

Ethical approval:Approved .

\section{REFERENCES}

1- Prasad A, Rabbani P, Abbasi A, Bowersox E and Fox M. Experimental zinc deficiency. Ann Intern Med; 1978; 89:483-490.

2- Riggio O, Merli M, Capocaccia L, Caschera M, Zullo A, Pinto G, et al. Zinc supplementation reduces blood ammonia and increases liver transcarbamylase activity in experimental cirrhosis. Hepatology; 1992; 16:785-789.

3- Yoshida A, Kobayashi K, Manya H, Taniguchi K, Kano H, Mizuno M, et al. Muscular dystrophy and neuronal migration disorder caused by mutations in a glycosyltransferase. Dev Cell; 2001; 1(5): 717-24.

4- Reding P, Duchateau J and Bataille C. Oral zinc supplementation improves hepatic encephalopathy. Results of a randomised controlled trial. Lancet; 1984; 2(8401): 493-495.

5- Schomerus H and Hamster W. Neuropsychological aspects of portal - systemic encephalopathy. Metab Brain Dis; 1998; 13: 361 - 377.

6- Kircheis G, Knoche A, Hilger N, Manhart F, Schnitzler A, Schulze $\mathrm{H}$, et al. Hepatic encephalopathy and fitness to drive. Gastroenterology; (2009); 137: 1706 - 1715.

7- Saxena N, Bhatia M, Joshi Y, Garg P and Tandon R. Auditory P300 event - related potentials and number connection test for evaluation of subclinical hepatic encephalopathy in patients with cirrhosis of the liver: A follow - up study. J. Gastroenterol. Hepatol; (2001); 16: 322 - 327.

8- Weissenborn K, Ennen J, Schomerus H, Ruckert $\mathrm{N}$ and Hecker H. Neuro-psychological characterization of hepatic encephalopathy. $J$ Hepatol; 2001; 34: 768 - 773.

9- Huber A, Ebner L, Heverhagen J and Christe A. State-of-the-art imaging of liver fibrosis and cirrhosis: A comprehensive review of current applications and future perspectives. European Journal of Radiology; 2015; 2: 90-100. 
10- Goeneweg M, Moerland W, Quero J, Hop W, Krabbe P and Schalm S. Screening of subclinical hepatic encephalopathy. J. Hepatology; 2000; 32: 748-53.

11- Dhiman R, Saraswat V, Sharma B, Sarin S, Chawla Y, Butterworth R, et al. Minimal hepatic encephalopathy: Consensus statement of a working party of the Indian National Association for Study of the Liver (2010) Journal of Gastroenterology and Hepatology; 2010; 25 : 1029-1041.

12- Grüngreiff K, Grüngreiff S and Reinhold D. Zinc deficiency and hepatic encephalopathy: results of a long term follow up on zinc supplementation. The Journal of Trace Elements in Experimental Medicine; 2000; 13:21-31.

13- Yang S, Lai Y, Chiang T, Chen DF and Chen DS. Role of zinc in subclinical hepatic encephalopathy: Comparison with somatosensory-evoked potentials. Journal of Gastroenterology and Hepatology; 2004; 19: 375-379.

14- Yang S, Wu C, Chen L, Mo S and Chen DF. Nutritional status in non-alcoholic subclinical porto-systemic encephalopathy. World J. Gastroenterol; 1998; 4: 380-4.

15- Weissenborn K, Ruckert N, Hecker H and Manns M. The number connection tests $\mathrm{A}$ and $\mathrm{B}$ : Interindividual variability and use for the assessment of early hepatic encephalopathy. $J$ Hepatol; 1998; 28(4): 646-53.
16- Abd El Wahab E, Mikheal A, Sidkey F and Shatat H. Factors associated with hepatitis C infection among chronic HCV Egyptian patients. Iran J Public Health; 2014; 43(11): 1510-1518.

17- Bakr I, Rekacewicz C, El-Hosseiny M, Ismail S, El-Daly M, El-Fafrawy S, et al. Higher clearance of hepatitis $\mathrm{C}$ virus infection in females compared with males. Gut; 2006; 55(8): 1183-1187.

18- Van der Rijt C, Schalm S, Schat H, Foeken K and De Jong G. Overt hepatic encephalopathy precipitated by zinc deficiency. Gastroenterology; 1991; 100: 1114-1118.

19- Tarantino G, Citro V, Esposito P, Giaquinto S, de Leone A, Milan G et al. Blood ammonia levels in liver cirrhosis: a clue for the presence of portosystemic collateral veins. BMC Gastroenterology; 2009; 9(21): 314-25.

20- Grungreiff $\mathrm{K}$ and Reinhold D. Zinc: a complementary factor in the treatment of chronic hepatitis C. Mol Med Report; 2010; 3: 371-75.

21- Triwikatmani C, Bayupurnama P, Maduseno S, Ratnasari N, Indrarti, F and Nurdjanah, S. Serum zinc level and urinary zinc excretion in patients with liver cirrhosis. The Indonesian Journal of Gastroenterology, Hepatology and Digestive Endoscopy; 2009; 10(1): 2-6.

22- Mousa N, Abdel-Razik A, Zaher A, Hamed M, Shiha G, Effat N, et al. The role of antioxidants and zinc in minimal hepatic encephalopathy: a randomized trial. Ther Adv Gastroenterol; 2016; 9(5): 684-691. 